\title{
Resisting Transnormativity: challenging the medicalization and regulation of trans bodies
}

\author{
Evan Vipond*
}

This paper investigates some of the medical and legal procedures and policies of sex reassignment within Canada and the United States. The leveraging of medical discourse in the fight for trans rights reinforces neoliberal discourses of individualism and equal rights. Through medicalization, gender-conforming trans persons are able to access treatment, such as hormone therapy and gender-confirming surgeries, while nonnormative trans persons are often denied services. Transnormative narratives of transition reinforce medical discourses of what it means to be trans and how to be trans. These narratives simultaneously legitimize transsexuality for those who can conform to the dominant narrative while delegitimizing gender variance and nonconforming trans persons. [Article copies available for a fee from The Transformative Studies Institute. E-mail address: journal@transformativestudies.org Website: http://www.transformativestudies.org (C2015 by The Transformative Studies Institute. All rights reserved.]

KEYWORDS: Transnormativity, Medicalization, Trans Rights, Neoliberalism.

When Jenna Talackova entered the 2012 Miss Universe Canada competition, she did not disclose her history of being born and assigned male at birth (nor should she have to). When the competition's

\footnotetext{
* Evan Vipond is pursing a Masters degree in Women and Gender Studies in collaboration with Sexual Diversity Studies at the University of Toronto. Evan's work focuses on transnormativity and trans medicalization. Evan received the Hallam Prize for Best Graduate Student in Sexual Diversity Studies in June 2014 and recently presented his work on transnormative narratives at the 2014 Eastern Sociological Society conference in Baltimore. In December 2012, Evan's monodrama "Period" was published in City Voices: A Book of Monologues by Toronto Artists. Evan attained a BA (honours) in Theatre Studies, with a certificate in Sexuality Studies from York University (2010). Address correspondance to: Evan Vipond, University of Toronto, 40 Willcocks Street, Wilson Hall, New College, Toronto, M5S 1C6, Canada; e-mail: e.vipond@mail.utoronto.ca.
} 